\title{
Serum immunoglobulin levels in male schizophrenic patients before and after olanzapine therapy
}

\author{
Mahmoud Khudhayer Oglah Hussein \\ Deptartment of Clinical Pharmacy, College of Pharmacy, University of Mosul

$\frac{\text { Received } \quad \text { Accepted }}{2.9 .2010 \quad 31.10 .2010}$

\begin{abstract}
Objective: To evaluate the effect of olanzapine therapy on serum immunoglobulin levels (IgA, $\operatorname{IgG}, \operatorname{IgM})$ in male schizophrenic patients after 2 months of treatment by olanzapine at a daily dose of $20 \mathrm{mg}$.

Patients and Methods: Twenty-eight patients with schizophrenia were included in this study, assessment of each case was done by a psychiatric, also included a 30 healthy subjects as a control group. Serum immunoglobulin concentrations were determined for both patients and controls by Mancini Radial Immuno-diffusion method using immunoglobulin kits. For the patients group and after 2 months therapy with olanzapine at a fixed daily dose of $20 \mathrm{mg}$, serum immunoglobulins were determined again using the same method for the assay.

Results: No significant difference was found between serum levels of immunoglobulin (IgA, IgG, IgM) in schizophrenic patients before therapy in comparison to controls. Also insignificant difference was found between serum immunoglobulin levels (IgA, IgG, IgM) in schizophrenic patients after 2 months of olanzapine therapy and the controls. By comparing serum immunoglobulin levels in patients with schizophrenia before and 2 months after starting olanzapine therapy, no statistically significant difference was found.
\end{abstract}

Conclusion: Olanzapine as atypical antipsychotic may not have an influence on the humoral immune response as reflected by the immunoglobulin levels (IgA, IgG, IgM) Keywords: Schizophrenia, immunoglobulin concentrations (IgG, IgA, IgM)

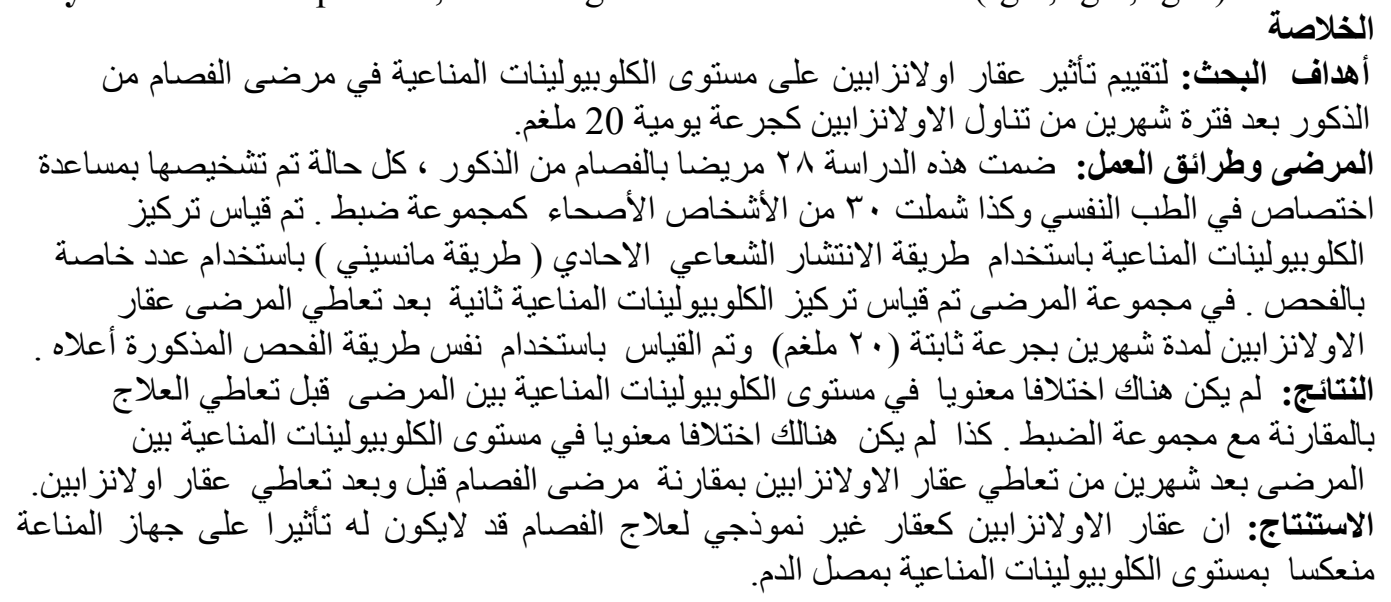

$S_{\text {debilitating and on of the most }}$ devastating illness known to man. It is a chronic condition that frequently has devastating effects on many aspects of the patient life and carries a high risk of suicide ${ }^{1}$.

\begin{abstract}
Many theories have been designed to explain the etiology of schizophrenia. One of these theories is dopamine hypothesis which is based on the discovery that agents that diminish dopaminergic activity also reduce the acute symptoms and sign of
\end{abstract}


psychosis specifically agitation, anxiety and hallucination ${ }^{2}$.

Olanzapine is atypical antipsychotic drug, used in the treatment of schizophrenia and it is as effective as typical drug against positive symptoms of schizophrenia \& more effective against negative symptoms with significant lower extrapyramidal side effects $^{3}$.

The basic function of immunoglobulins is to help the body protect itself against potential pathogens. Immunoglobulins has always been the subject of research in finding the relationship with psychotic disorders and few works with controversial results have been done in this respect ${ }^{4,5}$. Also some of the typical antipsychotic drugs have been noticed to affect the serum concentration of immunoglobulins ${ }^{6}$.

The aim of this study is to show the effect of atypical agents such as olanzapine on the serum immunoglobulin concentrations (IgG, IgA, IgM) in male schizophrenic patients.

\section{Patients and Methods}

Patients included in this study were referred cases from the outpatient clinic at Ibn-Seena hospital, Mosul city, Iraq by a specialist in psychiatry. Patients were selected according to certain criteria, which include, male case, newly diagnosed schizophrenic according to DSM-IV (Diagnosis and statistical of Manual Disorder -IV) criteria, with no other diseases. Twenty eight cases were included in the study, with an age ranged between 18 and 40 years (mean+SD $31.78+6.33$ years). Also included thirty apparently healthy male subjects with an age ranged between 18 and 40 years (mean \pm SD: $31.20 \pm 6.30$ years).

Before treatment a blood sample was taken for the patients and controls and assays of immunoglobulin levels (IgA, IgG, IgM) were done using Mancini Single Radial immunodiffusion method $^{7}$, using kits from Sanofi Diagnostics Company (France).

Then patients submitted on olanzapine $20 \mathrm{mg} / \mathrm{d}$ for 2 months after which another blood sample was taken and assay of serum immunoglobulin concentrations was done using the same kits and procedure.

Data are represented by mean \pm SD. Group mean differences were ascertained by using unpaired and paired t-test, P-value less than 0.05 were considered significant .

\section{Results}

By comparing immunoglobulin levels (IgA, IgG, IgM) between schizophrenic patients before therapy and the control, insignificant differences were found (Table 1).

By comparison of immunoglobulin levels between schizophrenic patients after 2 months of $20 \mathrm{mg} / \mathrm{d}$ olanzapaine therapy with the controls, insignificant difference were noted (Table 2).

Table 1. Comparison of immunoglobulin levels between schizophrenic patients before therapy and the controls.

\begin{tabular}{|c|c|c|c|}
\hline Parameters & $\begin{array}{c}\text { Patients } \\
\mathrm{N}=28\end{array}$ & $\begin{array}{c}\text { Control } \\
\mathrm{N}=30\end{array}$ & p-value \\
\hline Serum IgG mg/dl & $1061.78+156.58$ & $1063.66+164.89$ & $>0.05$ \\
\hline Serum IgA mg/dl & $233.92+32.35$ & $223+42.35$ & $>0.05$ \\
\hline Serum IgM mg/dl & $179.64+30.60$ & $177.66+22.75$ & $>0.05$ \\
\hline
\end{tabular}


Table 2. Comparison of immunoglobulin levels between schizophrenic patients after two months of olanzapine therapy and the controls.

\begin{tabular}{|c|c|c|c|}
\hline Parameters & $\begin{array}{c}\text { Patients after therapy } \\
\mathrm{N}=28\end{array}$ & $\begin{array}{c}\text { Control } \\
\mathrm{N}=30\end{array}$ & p-value \\
\hline Serum IgG mg/dl & $1065+153.05$ & $1063.66+164.89$ & $>0.05$ \\
\hline Serum IgA mg/dl & $233.57 \pm 29.21$ & $223 \pm \underline{42.35}$ & $>0.05$ \\
\hline Serum $\mathrm{IgM} \mathrm{mg/dl}$ & $177.14 \underline{23.38}$ & $177.66 \pm 22.75$ & $>0.05$ \\
\hline
\end{tabular}

By comparing serum immunoglobulin levels in schizophrenic patients before and 2 months after olanzapine therapy no significant differences were found (Table3).

Table 3. Comparison of immunoglobulin levels in schizophrenic patients before and 2 months after olanzapine therapy.

\begin{tabular}{|c|c|c|c|}
\hline Parameters & $\begin{array}{c}\text { Patients before therapy } \\
\mathrm{N}=28\end{array}$ & $\begin{array}{c}\text { Patients after } \\
\text { therapy N=28 }\end{array}$ & p-value \\
\hline Serum IgG mg/dl & $1061.78+156.58$ & $1065 \pm 153.05$ & $>0.05$ \\
\hline Serum IgA mg/dl & $233.92 \pm 32.35$ & $223.57 \pm 29.21$ & $>0.05$ \\
\hline Serum IgM mg/dl & $179.64+30.60$ & $177.14 \underline{+23.38}$ & $>0.05$ \\
\hline
\end{tabular}

\section{Discussion}

This study investigated the serum immunoglobulin levels (IgA, IgG, $\operatorname{IgM})$ in male schizophrenic patients and the effect of olanzapine "atypical antipsychotic therapy" at a daily dose of $20 \mathrm{mg}$ on their levels.

This study was conducted on male patient rather than female patient because of the difficulties associated with the follow up of female patient especially if the patient was pregnant, lactating or during menstruation.

The study demonstrated insignificant differences in the mean serum levels of immunoglobulins in schizophrenic patients before and after olanzapine therapy in comparison to controls.

Few studies have been done around the subject with controversial results. Going with our results, Rao et al concluded that there were no changes in the immunoglobulin levels in schizophrenic patients compared to healthy control $^{8}$. In accordance with this study, Muller \& Ackenheil reported that there is no significant differences in the CSF immunoglobulin levels between schizophrenic patients and controls? Long term treatment with chlorpromazine (typical antipsychotic) may develop one or more immunologic abnormalities such as elevation of serum $\operatorname{IgM}^{4}$. Atypical antipsychotic (olanzapine) in our study show no effect after 2 months treatment on immunoglobulins. Such result may be explained by the fact that olanzapine has different actions. While other study showed significant elevation in the serum IgG in psychotic patients and such elevation decreased with increased phenothiazine dosages ${ }^{10}$.

De Lisi et al, concluded that there were evidence for suppression of humoral immunity (low IgM concentration) in some psychiatric patients without treatment ${ }^{11}$.

Balaita et al, reported a statistically significant raise in the serum levels of $\mathrm{IgG}$ and $\operatorname{IgA}$ in patients with mania and depression ${ }^{12}$. While Bhatia et al, suggested in their study a 
significant decrease in $\operatorname{IgG}$ and $\operatorname{IgA}$ levels in schizophrenic patients ${ }^{13}$.

In one study conducted by Chong-Thim et al, serum IgG and IgM levels were significantly higher in schizophrenic patients while IgA levels were similar in healthy persons and patients $^{6}$. A recent study, conducted in 2005 by Karim et al, their results goes with our findings, reported no changes in the serum immunoglobulin concentrations in schizophrenic patients ${ }^{3}$. This might be the first study with regard therapy with olanzapine antipsychotic drug.

In conclusion, olanzapine as atypical antipsychotic drug may have no influence on humoral immune responses as reflected by the immunoglobulin serum levels.

\section{Acknowledgement}

We thank Dr. Mahfoodh Al-Nuaimi

(lecturer in Nineveh college of medicine university of Mosul) for patients' sample and data collection.

\section{References}

1- Endow-eyer RA, Mitchell MM, Lacro JO. Schizophrenia. In: KodaKimble, Anne M, Young LY, et al. ed. Applied Therapeutics: The clinical use of drugs. $7^{\text {th }}$ edition. NY: Lippincott Williams and Wilkins; 2005.

2- Braff DL. Schizophrenic disorders. In : Isselbacher $\mathrm{K}$, Braunwald $\mathrm{E}$, Wilson JD, et al. editors. Harrison's principle of internal medicine, $13^{\text {th }}$ edition. NY: McGraw Hill company; 1994.

3- Hale AS. Olanzapine . Br J Hosp Med 1997;58:442-445.

4- Zarrabi MH, Zucker S, Miller F, Derman RM ,Romano GS, Hartentt $\mathrm{JA}$ et al. Immunologic and coagulation disorders in chlorpromazine -treated patients. Ann intern Med 1979 91;(2):194199.
5- Hossain I, Saddat N, Hossain K, et al. Serum immunoglobulin profile in somatization disorder patients. German J Psychiat . http://www.gjpsy.uni.goettingen.de

6- Chong-Thim W, Wing-Foo T, Nilmani S. Serum immunoglobulin in Chinese male schizophrenics. Schizophr Res 1993;10(1):61-66.

7- Mancini G, Carbonara AO, and Heremans JF, Immunochemical quantitation of antigens by single radial immunodiffusion .Immunochemist 1965;2:235-254.

8- Roa IV, Gopinath PS, Jayasimha $\mathrm{N}$, et al . Immunochemical profiles in schizophrenia .NIMHANS J 1988;6:27-28.

9- Muller N. Acknheil M. Immunoglobulin and albumin content of cerebrospinal fluid in schizophrenic patients: relationship to negative symptomatology. Schizophr Res 1994;14:223-228.

10- John M. Gowdy MD. Immunoglobulin levels in psychotic patients Psychosomatics 1980;21:751-756.

11- De Lisi LE, King AC, Targum S. Serum immunoglobulin concentration in patients admitted to an acute psychiatric in- patient service. $\mathrm{Br} \mathrm{J}$ Psychiat 1984;145:661-665.

12- Balaita C, Iscrulescu C, Sarbulescu A. Serum immunoglobulin levels in schizoaffective disorders (manic and Depressive). Rom J Neurol Psychiatry 1992;30(1):63-71.

13- Bahatia MS, Dhar NK , Agrawal P. Khurana SK, Neena B, Malik SC. Immunoglobulin profile in schizophrenia . Indian J Med Sci 1992; 46:239-242. 